\title{
Effect of Azo Dyes on the Thermal Degradation of Post-consumer Polyester Fabrics
}

\author{
Dan QIN ${ }^{\mathrm{a}}$, Chaosheng $\mathrm{WANG}^{\mathrm{b}}$ and Huaping WANG ${ }^{\mathrm{c}}$ \\ State Key Laboratory for Modification of Chemical Fibers and Polymer Materials, College of \\ Materials Science and Engineering, Donghua University, Shanghai 201620, China \\ atiffiny_qin@163.com, ${ }^{b}$ cswang@dhu.edu.cn, ${ }^{\mathrm{c}}$ wanghp@dhu.edu.cn
}

\begin{abstract}
Thermogravimetric analysis(TGA) and pyrolysis gas chromatography mass spectrometry (Py-GC-MS) investigations were carried out on the thermal degradation of white and red post-consumer polyester fabrics. The results show that red PET fabrics which was dyed with C.I. Disperse red 167 for its typical azo structure exhibits larger activation energy compared with white PET. The addition of azo dyes displays an inhibiting effect on the deep pyrolysis and the formation of biphenyl and bis(2-hydroxybutyl) terephthalate produced by the free radical mechanism.
\end{abstract}

Keywords: Post-consumer polyester fabrics, Azo dyes, Thermal degradation.

\section{Introduction}

Recycling of post-consumer polyester fabrics is the key to solve the dual problem of resource shortage and environmental pollution caused by the enormous post-consumer products including fabrics. It is important to investigate the effect of dyes on the degradation for most post-consumer PET products are dyed fabrics. In order to study the effect of dyes on the PET thermal degradation, C.I. Disperse red 167 with typical azo structure was used to dye white PET post-consumer fabrics for azo dyes accounting for the majority of textile production. Thermogravimetric analysis(TGA) and pyrolysis gas chromatography mass spectrometry (Py-GC-MS) were used to illustrate the effect of azo dyes in degradation mechanism based on activation energy and pyrolysis products.

\section{Experimental}

\section{Materials}

White post-consumer polyester fabrics with the intrinsic viscosity of $0.661 \mathrm{dl} / \mathrm{g}$ and C.I. Disperse red 167 (C.I.167) with molecular weight of 520g/mol were provided by Quanzhou Haitian Material Technology Corporation(China).

\section{Dyeing Process}

The red PET fabrics was dyed with $2 \%$ owf C.I.167 in a infrared dyeing machine (Texam Co., Ltd.,). The dye uptake of the product is $86.9 \%$. In the following sections of the 
paper, white post-consumer polyester fabrics and red PET fabrics are labeled as white PET and red PET for simplicity.

Thermogravimetric Analysis(TGA)

A Netzsch STA429 TG analyzer was used to obtain weight loss data. In each case, a $4 \pm$ $0.1 \mathrm{mg}$ sample was examined under nitrogen gas at temperature ranging from room temperature to $800{ }^{\circ} \mathrm{C}$, at heating rates of $5,10,20$ and $40{ }^{\circ} \mathrm{C} / \mathrm{min}$, respectively.

Pyrolysis-gas Chromatography Mass-spectrometry (Py-GC-MS)

Py-GC-MS was carried out to obtain detailed information on the volatile pyrolysis products and to study the degradation mechanism of C.I.167 and PET. Samples were decomposed in the PY2020iD pyrolyzer (Frontier Laboratories, Japan) at $420^{\circ} \mathrm{C}$ (the highest degradation rate of PET based on TGA) and $600^{\circ} \mathrm{C}$. The separation system was carried out using QP-2010 GCMS (Shimadzu Corp., Japan). The column temperature was programmed as follows: $40^{\circ} \mathrm{C}, 5$ minutes isothermal, $10^{\circ} \mathrm{C} /$ minute to $300^{\circ} \mathrm{C}$ and held at $300^{\circ} \mathrm{C}$ for $10 \mathrm{~min}$.

\section{Result and Discussion}

Thermal Degradation Mechanism of C.I. Disperse red 167

Py-GC-MS measurement was carried out in order to analyze the degradation mechanism of C.I. Disperse red 167. The main pyrolysis products at different temperatures are shown in Table 1. It can be inferred that the scission of $\mathrm{N}=\mathrm{N}$ bond and $\mathrm{C}-\mathrm{O}$ bond could lead to the formation of product acetic acid and 1-amino-2-chloro-4-nitrobenzene. Carbon dioxide could be observed at higher temperature for the further degradation of acetic acid. Therefore, the assumed degradation mechanism of C.I. 167 is shown in Figure 1.

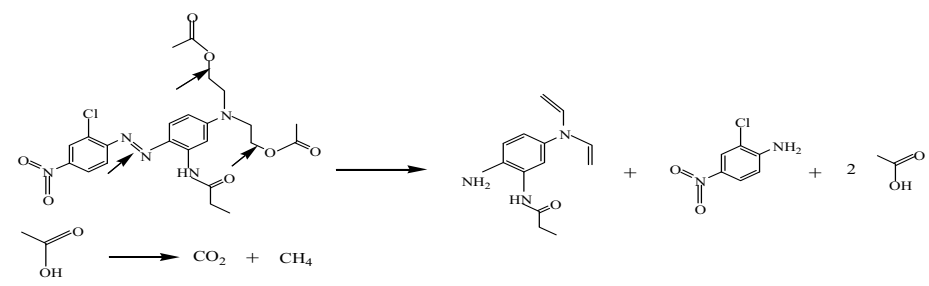

Figure 1 Assumed degradation mechanism of C.I. Disperse red 167

TABLE 1 MAIN PYROLYSIS PRODUCTS OF C.I. DISPERSE RED 167 AT DIFFERENT

TEMPERATURES

\begin{tabular}{|c|c|c|c|c|}
\hline \multirow{2}{*}{ Peak No. } & \multirow{2}{*}{ Products } & \multirow{2}{*}{ Molecular structure } & \multicolumn{2}{|c|}{ Area[\%] } \\
\hline & & & $420^{\circ} \mathrm{C}$ & $600^{\circ} \mathrm{C}$ \\
\hline 1 & Acetic acid & $\mathrm{OH}$ & 10.28 & 8.16 \\
\hline 2 & $\begin{array}{c}\text { 1-amino-2-chloro-4- } \\
\text { nitrobenzene }\end{array}$ & $\|_{0}^{\|}$ & 59.43 & 34.1 \\
\hline 3 & Carbon dioxide & $\mathrm{O}=\mathrm{C}=\mathrm{O}$ & - & 9.53 \\
\hline
\end{tabular}


Thermal Degradation Kinetics of White and Red PET

Flynn-Wall-Ozawa(FWO) method [1,2]was carried out to determine the apparent activation energy $E_{\alpha}$.Four series of TGA data obtained at heating rates of 5, 10, 20 and $40^{\circ} \mathrm{C} / \mathrm{min}$ were used. The relationship between activation energy $\mathrm{E}_{\alpha}$ and different conversation degree $\alpha$ is shown in Figure 2. The activation energy of both samples increases with the conversion degree $\alpha$ and the $\mathrm{E}_{\alpha}$ value of red PET is always larger than that of white PET, suggesting the improvement of thermal stability in addition of azo dyes.

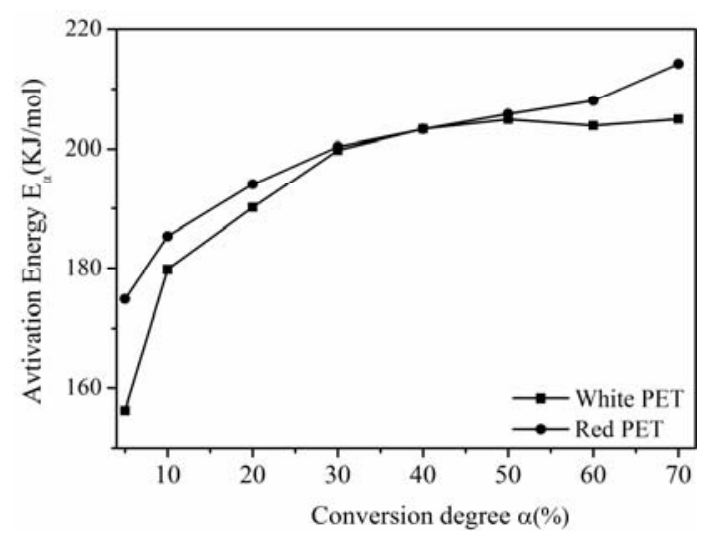

Figure 2 Activation energy $\mathrm{E}_{\alpha}$ of white and red PET in different conversion degree $\alpha$

Effect of Azo Dyes on the Thermal Degradation of PET

Py-GC-MS measurement was used to study the effect of C.I.167 on PET and two different temperatures $\left(420^{\circ} \mathrm{C}\right.$ and $\left.600^{\circ} \mathrm{C}\right)$ were investigated. The main pyrolysis products are listed in Table 2, which can be studied on the basis of the pyrolysis mechanism of PET existing [3-11].

TABLE 2 MAIN PYROLYSIS PRODUCTS OF WHITE AND RED PET AT $420^{\circ} \mathrm{C}$ AND $600^{\circ} \mathrm{C}$

\begin{tabular}{|c|c|c|c|c|c|c|}
\hline \multirow{2}{*}{$\begin{array}{l}\text { Peak } \\
\text { No. }\end{array}$} & \multirow{2}{*}{ Products } & \multirow{2}{*}{ Molecular structure } & \multicolumn{2}{|c|}{$\begin{array}{c}\text { Area at } \\
420^{\circ} \mathrm{C}[\%]\end{array}$} & \multicolumn{2}{|c|}{$\begin{array}{c}\text { Area at } \\
600^{\circ} \mathrm{C}[\%]\end{array}$} \\
\hline & & & White & Red & $\begin{array}{c}\text { Whit } \\
\text { e }\end{array}$ & Red \\
\hline 1 & Acetaldehyde & 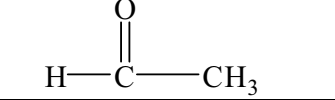 & 7.35 & 5.88 & - & - \\
\hline 2 & Benzene & & - & - & 5.63 & 0.83 \\
\hline 3 & $\begin{array}{c}\text { Phenylethylen } \\
\text { e }\end{array}$ & $\mathrm{CH}=\mathrm{CH}_{2}$ & - & - & 0.82 & - \\
\hline
\end{tabular}




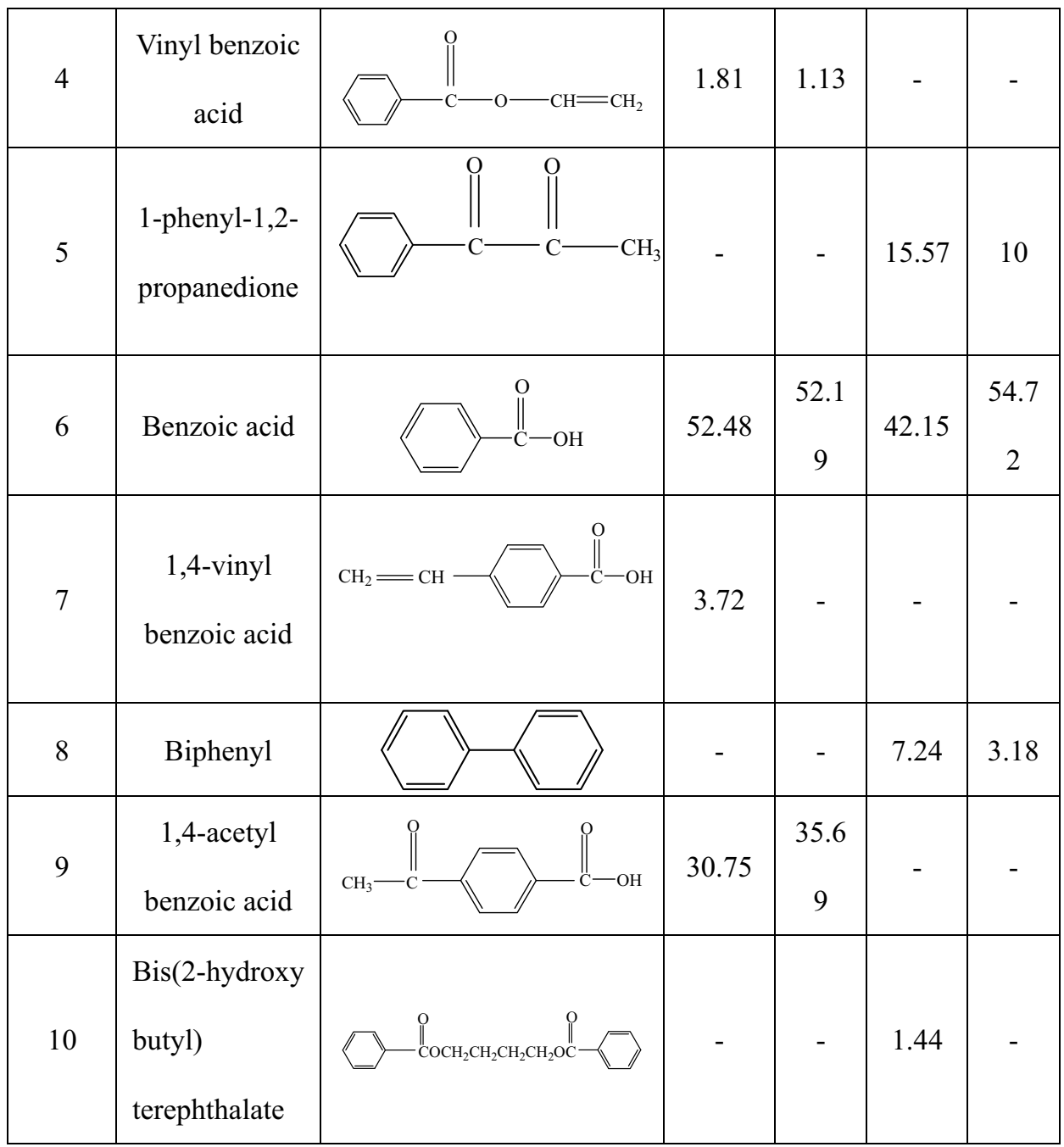

The initial step in PET degradation is the formation of vinyl and carboxylic acid end groups through the random ester scission from a stable six-membered ring transition state by $\beta$-hydrogen transfer [Figure 3(a)]. Then vinyl end groups (A) and carboxylic acid end groups (B) produced earlier would undergo two ways of ester scission indicated by arrows to form smaller molecules, such as products $\mathrm{C}$ and $\mathrm{D}$ [Figure 3(b-c)]. The product of $\mathrm{C}$ and $\mathrm{D}$ could be decomposed further by the reaction shown in Figure 4. It is a competitive relationship between the rearrangement reaction where acetophenone $(\mathrm{E})$ is formed and the decarboxylation generating the products of No.4 and No.7 [Figure 4(a)]. Product No.4 is an unstable product and could be decomposed into benzoic acid, phenylethylene and acetophenone at the temperature higher than $420^{\circ} \mathrm{C}$ for the phenomenon that product No. 4 disappears and products of No.2 (benzene) produced by decarboxylation of benzoic acid[Figure 4(b)] and No.3 (phenylethylene) come to appear at $600^{\circ} \mathrm{C}$, indicating higher temperature promotes the reaction.

The decrease for the content of benzene, the ultimate product of deep pyrolysis, in red PET in contract to that of white PET illustrates the addition of azo dyes displays an inhibiting effect on the deep pyrolysis. The possible reason may be the carboxyl group is consumed by the amidogen from the pyrolysis of C.I.167. Besides, the similar adverse 
effect could be found in the decarboxylation reactions generating products of No.3, No.4 and No.7 for the decrease of decarboxylate content in the presence of azo dyes.

The generation of acetaldehyde would undergo three kinds of routes: a) the reaction between the products in the formation of ester scission from the middle of the polymer chain mentioned earlier [Figure 3(a)] , b) the conversion of the vinyl end group and c) from the hydroxyl end group [10]. Acetaldehyde is no longer be detected as temperature rises to $600^{\circ} \mathrm{C}$ indicating that lower temperature is beneficial to the reaction. Acetaldehyde content of red PET is down to $5.88 \%$ suggesting the adverse influence on the reaction for the formation of acetaldehyde.

The reduction of the content of product No.8 (biphenyl) which is generated by the free radical mechanism [Figure 5(a)] in presence of dyes could be observed in Table 2. The free radical may be seized by the $\mathrm{N}=\mathrm{N}$ bond from azo dyes and the content of the compound producing by the free radical reaction should be reduced as a result. Besides, neither acetophenone nor biphenyl could be found at $420^{\circ} \mathrm{C}$ while biphenyl exits at higher temperature $600^{\circ} \mathrm{C}$, which illustrates the reaction is promoted by raising temperature. The same explanation could be attributed to the decrease for the content of product No.10 in red PET. Botelho G [11] claimed that there was probably another way for ester scission besides the tradition pattern [Figure 5(b)], which could be verified by the existence of $1.44 \%$ product No.10 at $600^{\circ} \mathrm{C}$. The addition of azo dyes may have an adverse effect on the reaction for it couldn't be observed in red PET.

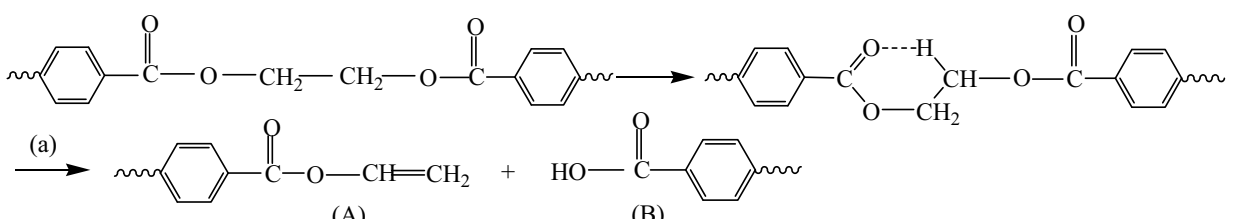

(A)

(B)
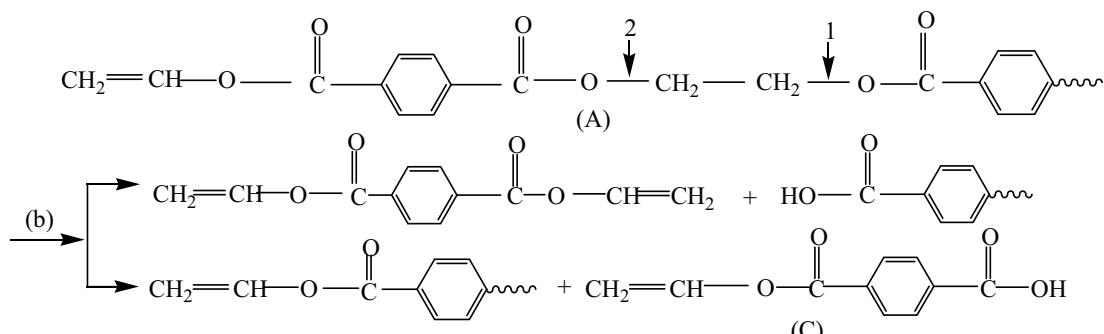

(C)

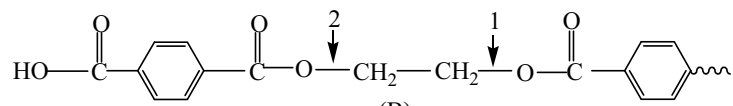

(B)

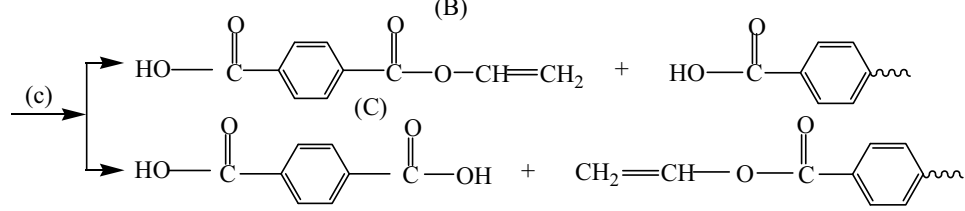

(D)

Figure 3 Primary thermal decomposition mechanisms of PET 


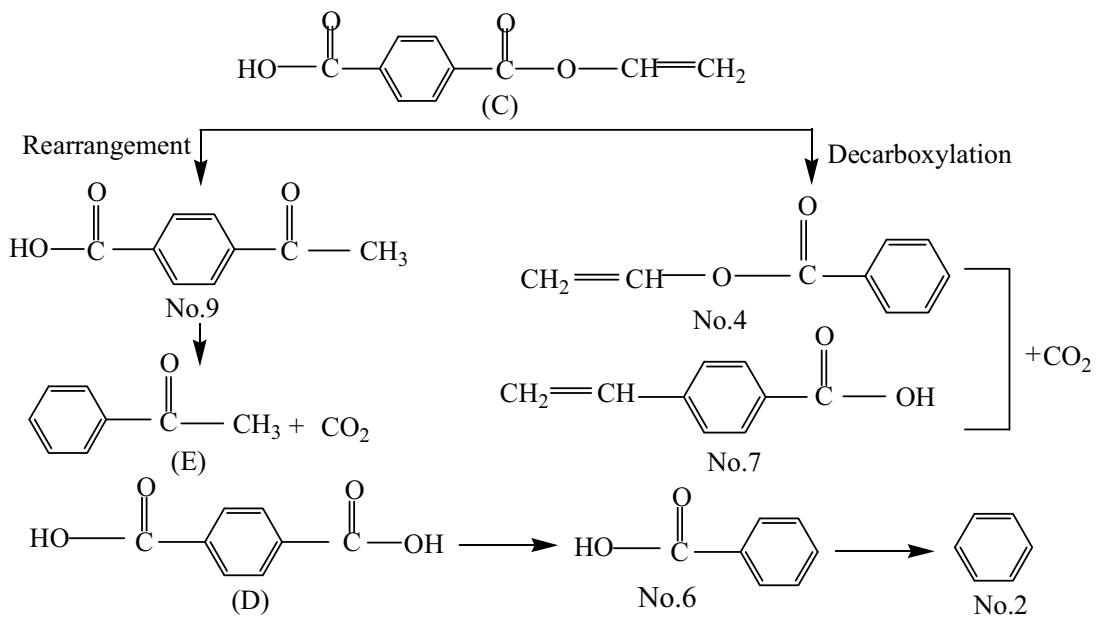

(a)

Figure 4 The degradation mechanism of product $\mathrm{C}$ and $\mathrm{D}$

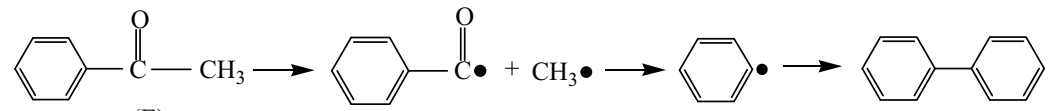

(E) No.8<smiles>O=C(O[CH]CCOC(=O)c1ccccc1)c1ccc(-c2ccc(C(=O)OCCOC(=O)c3ccccc3)cc2)cc1</smiles><smiles></smiles>

Figure 5 Free radical reactions generating biphenyl and bis(2-hydroxybutyl) terephthalate

\section{Conclusions}

A comparative study was conducted into the thermal degradation of white and red PET fabric by the measurements of TGA and Py-GC-MS. TGA results show that the addition of azo dyes (C.I. Disperse 167) may improve thermal stability. Py-GC-MS analysis shows that deep pyrolysis generating small molecules such as benzene and phenylethylene and the free radical reactions producing biphenyl and bis(2-hydroxybutyl) terephthalate are promoted while the formation of acetaldehyde is suppressed by the increase of temperature. The addition of azo dyes displays an inhibiting effect on the deep pyrolysis producing benzene probably for the reason that the carboxyl group is consumed by the amidogen from the pyrolysis of C.I.Disperse red 167. Besides, the similar adverse influence could be found in the decarboxylation reactions generating phenylethylene, vinyl benzoic acid and 1,4-vinyl benzoic acid. The free radical could be seized by the $\mathrm{N}=\mathrm{N}$ bond from the azo dyes and the content of biphenyl and bis(2-hydroxybutyl) terephthalate produced by the free radical mechanism would be reduced as a result during thermal degradation. 


\section{Acknowledgments}

This work was supported by the Fundamental Research Funds for the Central Universities (No. 2232013D3-17).

\section{References}

1. Ozawa T, A new method of analyzing thermogravimatric data, Bull Chem Sco Jpn.38(1965) 1881-1886.

2. Flynn J H, Wall L A,A quick direct method for the determination of activation energy from thermogravimetric data, Polym Letter.4(1966) 323-328.

3. P.Chang,C.A.Wilkie,A mechanism for flame retardation of poly(etheylene terephthaltate), J. Appl. Polym. Sci.38(1989)2245-2252.

4. Bednas,M.E.,Day,M.,Ho,K., Sander,R.,Wiles,D.M, J Appl Polym Sci.26(1981)277.

5. McNeil,I.C., Bounekhel, M. Polym Degrad Stab.34(1991)187.

6. Passalacqua V, Pilati F, Zamboni V, Fortunato B, Manaresi P. Polymer 17(1976)1044.

7. Montaudo,G., Puglisi, C., Samperi,F. Polym Degrad Stab .42(1993)13.

8. Filippo Samperi, Concetto Puglisi, Rossana Alicata, Giorgio Montaudo, Thermal degradation of poly(ethylene terephthalate) at the processing temperature, Polymer Degradation and Stability.83(2004) 3-10.

9. B.J.Holland, J.N.Hay, The thermal degradation of PET and analogous polyesters measured by thermal analysis-Fourier transform infrared spectroscopy, Polymer. 43(2002)1835-1847.

10. Kishan C.Khemani, A novel approach for studying the thermal degradation, and for estimating the rate of acetaldehyde generation by the chain scission mechanism in ethylene glycol based polyesters and copolyesters, Polymer Degradation and Stability. 67 (2000) 91-99.

11. Botelho G, Queiros A, Liberal S, Gijsman P. Studies on thermal and thermal-oxidative degradation of poly(ethylene terephthalate) and poly(butylene terephthalate), Polym Degrad Stab.74(2001)39-48. 